\title{
Modelling and simulation of a solar absorption cooling system for India
}

\author{
V Mittal \\ Mechanical Engineering Department, BRCM College of Engineering and Technology, Bahal
}

\section{K S Kasana}

Mechanical Engineering Department, NIT, Kurukshetra

\section{N S Thakur}

Mechanical Engineering Department, NIT, Hamirpur

\begin{abstract}
This paper presents modelling and simulation of a solar absorption cooling system. In this paper, the modelling of a solar-powered, single stage, absorption cooling system, using a flat plate collector and water-lithium bromide solution, is done. A computer program has been developed for the absorption system to simulate various cycle configurations with the help of various weather data for the village Bahal, District Bhiwani, Haryana, India. The effects of hot water inlet temperatures on the coefficient of performance (COP) and the surface area of the absorption cooling component are studied. The hot water inlet temperature is found to affect the surface area of some of the system components. Moreover the effect of the reference temperature which is the minimum allowable hot water inlet temperature on the fraction of total load met by non-purchased energy (FNP) and coefficient of performance (COP) is studied and it is found that high reference temperature increases the system COP and decreases the surface area of system components but lower reference temperature gives better results for FNP than high reference temperatures.
\end{abstract}

Keywords: solar absorption, flat plate collector, water-lithium bromide solution, cooling, simulation
I solar insolation $\left(\mathrm{W} / \mathrm{m}^{2}\right)$

$\mathrm{k}$ heat conductivity $(\mathrm{W} / \mathrm{mK})$

$\mathrm{m} \quad$ mass flow rate $(\mathrm{kg} / \mathrm{s})$

Q heat transfer rate (W)

Quux auxiliary heater capacity (kW)

$\mathrm{Q}_{\mathrm{L}} \quad$ extracted energy from the storage tank $(\mathrm{kW})$

Qload generator load (kW)

$\mathrm{Q}_{\mathrm{u}} \quad$ useful energy $(\mathrm{kW})$

$\mathrm{T}$ temperature $(\mathrm{K})$

$\mathrm{T}_{\text {in }} \quad$ collector inlet temperature $(\mathrm{K})$

$\mathrm{T}_{\mathrm{O}}$ the environment temperature $(\mathrm{K})$

$\mathrm{T}_{\text {ref }} \quad$ reference temperature $(\mathrm{K})$

$\mathrm{T}_{\mathrm{S}} \quad$ storage tank temperature $(\mathrm{K})$

$\mathrm{U}_{\mathrm{L}} \quad$ overall heat transfer coefficient $\left(\mathrm{W} / \mathrm{m}^{2} \mathrm{~K}\right)$

$\mathrm{X}$ weight fraction of $\mathrm{LiBr}-\mathrm{H}_{2} \mathrm{O}$ solution

$\mathrm{C}_{\mathrm{v}} \quad$ specific heat at constant volume

$\eta_{\mathrm{c}} \quad$ collector efficiency

$\Delta \mathrm{t}$ time period $(\mathrm{h})$

$\tau \quad$ transmittance

$\alpha \quad$ absorptance

\section{Subscript}

$\begin{array}{ll}\text { f } & \text { liquid (fluid) } \\ \text { S } & \text { storage tank } \\ \text { v } & \text { vapour } \\ \text { w } & \text { water }\end{array}$

\section{Introduction}

The energy demand for refrigeration and air-conditioning to control temperature and humidity and for the provision of fresh air has increased continuously during the last few decades especially in developing countries like India. This increase is caused amongst other reasons by increased thermal loads, 
occupant comfort demands, and architectural trends. This has been responsible for the escalation of electricity demand and especially for the high peak loads due to the use of electrically driven vapour compression machines. Moreover, the consumption of primary energy and the emissions of greenhouse gases associated with electricity generation from fossil fuels lead to considerable environmental consequences and monetary costs. Conventional energy will not be enough to meet the continuously increasing need for energy in the future. In this case, renewable energy sources will become important.

An alternative solution for this problem is solar energy, available in most areas and representing a good source of thermal energy. Of the various solar air conditioning alternatives, the absorption system appears to be one of the most promising methods (Wilbur \& Mitchell 1975). The absorption cycle is similar in certain respect to the electrically driven vapour compression machines. Of the various solar absorption air conditioning systems, $\mathrm{LiBr}-\mathrm{H}_{2} \mathrm{O}$ and $\mathrm{H}_{2} \mathrm{O}-\mathrm{NH}_{3}$ are the major working fluid pairs available in these systems. It is reported that the $\mathrm{LiBr}$ $\mathrm{H}_{2} \mathrm{O}$ pair has a higher COP than any other pair of the working fluids. The $\mathrm{LiBr}-\mathrm{H}_{2} \mathrm{O}$ system operates at a generator temperature in the range of 343 to $368 \mathrm{~K}$ with water used as a coolant in the absorber and condenser. The COP of the system is between 0.6 and 0.8 (Duffie \& Beckman, 1991). The major components in the $\mathrm{LiBr}-\mathrm{H}_{2} \mathrm{O}$ solar absorption cooling systems are the chillers and solar collectors. Many researchers have developed solar assisted absorption refrigeration systems. Most of them have been produced as experimental units and computer codes were written to simulate the systems. Some of these designs are presented here.

Hammad and Audi (1992) described the performance of a non-storage, continuous, solar operated absorption refrigeration cycle. The maximum ideal coefficient of performance of the system was determined to be equal to 1.6, while the peak actual coefficient of performance was determined to be equal to 0.55 .

Haim et al. (1995) performed a simulation and analysis of two open-cycle absorption systems. Both systems comprised a closed absorber and evaporator as in conventional single stage chillers. The regenerator, used to reconcentrate the absorber solution by means of solar energy, makes up the open part of the cycle. The analysis was performed with a computer code developed for modular simulation of absorption systems under varying cycle configurations (open- and closed- cycle systems) and with different working fluids. Based on the specified design features, the code calculates the operating parameters in each system. Results indicate a definite performance advantage of the directregeneration system over the indirect one.
Hawlader et al. (1993) developed a $\mathrm{LiBr}$ absorption cooling system employing an $11 \times 11 \mathrm{~m}^{2}$ collector/regenerator unit. They also developed a computer model, which they validated against actual experimental values with good agreement. The experimental results showed a regeneration efficiency varying between 38 and $67 \%$ and the corresponding cooling capacities ranged from 31 to 72 $\mathrm{kW}$.

Ameel et al. (1995) gives performance predictions of alternative low-cost absorbents for open cycle absorption using a number of absorbents. The most promising of the absorbents considered was a mixture of two elements, lithium chloride and zinc chloride. The estimated capacities per unit absorber area were $50-70 \%$ less than those of lithium bromide systems.

In order to improve the system design of a solar powered absorption air conditioning system, a parametric study must be carried out to investigate the influence of key parameters on the overall system performance. If experiments were used to perform the parametric study, effects of one key parameter on the overall system performance would normally require several cooling seasons and hence years to establish a conclusion. Also, it is extremely difficult to keep the performance of the system components constant over the entire experimental period as the components deteriorate with time. Therefore, it is extremely difficult and expensive to carry out experiments to investigate the influence of all the key parameters on the overall system performance of an existing solar cooling system. The objective of this study is to model a complete solar absorption cooling system, comprised of a solar collector, storage tank and a $\mathrm{LiBr}$-water absorption chiller and to develop a simulation program for parametric study of this system. The program is used to simulate the cooling system with the help of meteorological data for Bahal, Dist Bhiwani, Haryana (India), as shown in Table 1.

In the present work, modelling and simulation is done for proper sizing of flat-plate solar collectors with a water storage tank to match the load needed to the generator of the absorption system. The performance of a $10.5 \mathrm{~kW}$ solar driven $\mathrm{LiBr}-\mathrm{H}_{2} \mathrm{O}$ absorption cooling system is investigated numerically. In section 2 , mathematical modelling of a solar absorption cooling system is provided. In the mathematical modelling section, modelling of an absorption system as well as that of the solar collector system is also provided. Section 3 presents the results and discussion pertaining to the validation of code. Section 4 concludes the work.

\section{Mathematical model of solar absorption cooling system}

Figure 1 shows the schematic diagram of a basic solar absorption cooling system. This system has 
Table 1: Solar insolation, I (W/m²), for Bahal, India

\begin{tabular}{lccccc}
\hline Time & \multicolumn{5}{c}{ Solar insolation $\left(\mathrm{W} / \mathrm{m}^{2}\right)$} \\
\hline & May & June & July & August & Sept. \\
\hline $7: 00$ & 119.44 & 113.88 & 77.77 & 77.77 & 44.44 \\
\hline $8: 00$ & 288.88 & 261.10 & 227.77 & 208.32 & 166.66 \\
\hline 9:00 & 480.54 & 427.76 & 377.76 & 358.32 & 297.21 \\
\hline $10: 00$ & 633.31 & 558.31 & 458.32 & 455.54 & 419.43 \\
\hline $11: 00$ & 755.53 & 666.6 & 530.54 & 541.65 & 522.20 \\
\hline $12: 00$ & 799.97 & 711.09 & 580.53 & 583.31 & 563.87 \\
\hline $13: 00$ & 805.53 & 716.64 & 608.31 & 594.42 & 583.31 \\
\hline $14: 00$ & 755.53 & 647.20 & 561.09 & 530.54 & 522.20 \\
\hline $15: 00$ & 597.20 & 538.87 & 474.98 & 491.65 & 413.87 \\
\hline $16: 00$ & 441.65 & 372.21 & 386.10 & 363.87 & 333.32 \\
\hline $17: 00$ & 261.10 & 238.88 & 233.32 & 191.66 & 197.21 \\
\hline $18: 00$ & 105.55 & 99.99 & 111.10 & 69.44 & 55.55 \\
\hline
\end{tabular}

been the basis of most of the experience to date with solar air conditioning. Here, the solar energy is gained through the collector and is accumulated in the storage tank. Then, the hot water in the storage tank is supplied to the generator to boil off water vapour from a solution of Lithium Bromide and water. The water vapour is cooled down in the condenser and then passed to the evaporator where it again is evaporated at low pressure, thereby pro- viding cooling to the required space.

Meanwhile, the strong solution leaving the generator to the absorber passes through a heat exchanger in order to preheat the weak solution entering the generator. In the absorber, the strong solution absorbs the water vapour leaving the evaporator. Cooling water from the cooling tower removes the heat by condensation. Since the temperature of the absorber has a higher influence on the efficiency of the system than the condensing temperature, the heat rejection (cooling water) fluid, is allowed to flow through the absorber first and then to the condenser. An auxiliary energy source is provided, so that hot water is supplied to the generator when solar energy is not sufficient to heat the water to the required temperature level needed by the generator. The mathematical modelling of the complete solar assisted absorption cooling system requires modelling of solar collector systems separately.

\subsection{Absorption cooling system modelling Energy balance}

The system is modelled by treating each of the major components i.e. the generator, condenser, evaporator, heat exchanger and absorber as single control volumes. The heat addition or rejection at each component is then obtained by taking an energy balance across each component.

The rate of heat addition in the generator is the energy input to the cycle is given by the following equation:

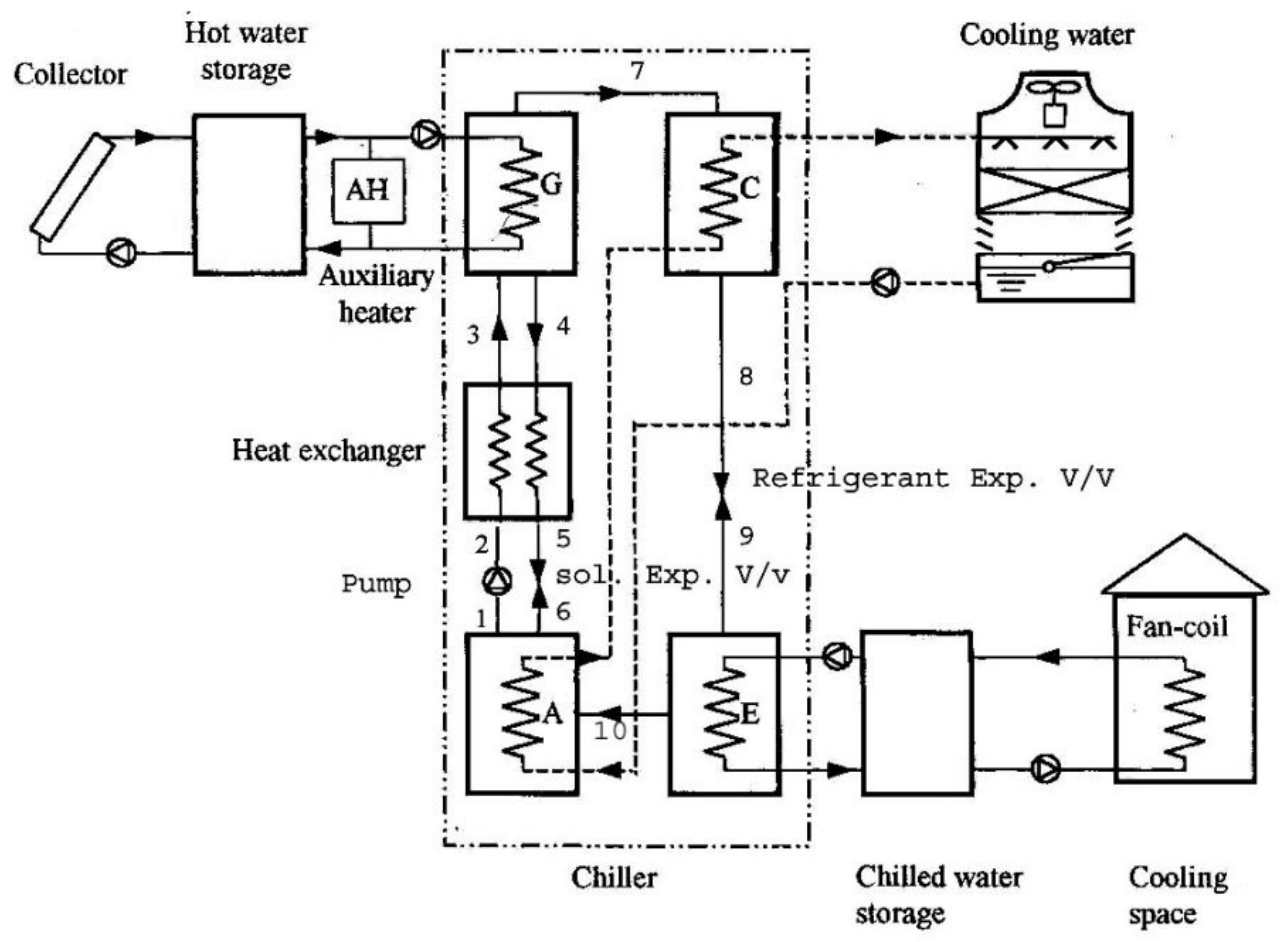

Figure 1: A basic solar absorption cooling system 


$$
Q_{\text {gen }}=m_{7} h_{7}+m_{4} h_{4}-m_{3} h_{3}
$$

The rate of heat rejection out of the condenser is given by the following equation:

$$
\mathrm{Q}_{\text {con }}=\mathrm{m}_{7} \mathrm{~h}_{7}-\mathrm{m}_{8} \mathrm{~h}_{8}
$$

The rate of heat absorption in the evaporator is given by the following equation:

$$
Q_{\text {evap }}=\mathrm{m}_{10} \mathrm{~h}_{10}-\mathrm{m}_{9} \mathrm{~h}_{9}
$$

The rate of heat rejection by the absorber is given by the following equation:

$$
Q_{a b s}=m_{10} h_{10}+m_{6} h_{6}-m_{1} h_{1}
$$

An energy balance on the hot side of the solution heat exchanger is given by the following equation:

$$
\mathrm{Q}_{\text {shx-h }}=\mathrm{m}_{4} \mathrm{~h}_{4}-\mathrm{m}_{5} \mathrm{~h}_{5}
$$

Similarly an energy balance on the cold side of the solution heat exchanger is given by the following equation:

$$
\mathrm{Q}_{\text {shx-c }}=\mathrm{m}_{3} \mathrm{~h}_{3}-\mathrm{m}_{2} \mathrm{~h}_{2}
$$

The overall energy balance on the solution heat exchanger is satisfied if $Q_{\text {shx-h }}=Q_{\text {shx-c }}$ which is seen to be the case here.

Coefficient of performance (COP) is defined according to Figure 1 as follows:

$$
C O P=Q_{\text {evap }} / Q_{\text {gen }}
$$

Usually the enthalpy of the refrigerant (water) is calculated by using the saturated and superheated property tables. The following formulations suggested by Stoeker and Jones (1982) have a great advantage for computer simulation of the system performance.

The enthalpy at exit of condenser (State 8) is given as:

$$
\mathrm{H}_{8}=\mathrm{h}_{\mathrm{f}}\left(\mathrm{T}_{\mathrm{c}}\right)=\mathrm{A}+\mathrm{BT}_{\mathrm{c}}+\mathrm{CT}_{\mathrm{c}}^{2}
$$

The enthalpy at the exit of the evaporator (State 10) is given as:

$$
\mathrm{H}_{10}=\mathrm{h}_{\mathrm{v}}\left(\mathrm{T}_{e}\right)=\mathrm{A}+\mathrm{BT}_{e}+\mathrm{CT}_{e}^{2}
$$

The enthalpy at the exit of the generator (State 7) is given as:

$$
\mathrm{H}_{2}=\mathrm{h}_{\mathrm{v}}\left(\mathrm{T}_{\mathrm{g}}\right)=\mathrm{A}+\mathrm{BT}_{\mathrm{g}}+\mathrm{CT}_{\mathrm{g}}^{2}
$$

The enthalpies of the solution of the refrigerant and the absorbent $\left(\mathrm{H}_{2} \mathrm{O}-\mathrm{LiBr}\right)$ at states 1 and 4 are expressed in a multi-variable polynomial in terms of the solution temperature, $\mathrm{T}\left({ }^{\circ} \mathrm{C}\right)$, and solution concentration, $\mathrm{X}$, through the absorber and generator unit as given in ASHRAE charts by:

$$
h=\sum_{0}^{4} A_{n} X^{n}+T \sum_{0}^{4} B_{n} X^{n}+T^{2} \sum_{0}^{4} C_{n} X^{n}
$$

Where $\mathrm{A}, \mathrm{B}$ and $\mathrm{C}$ are constant coefficients and are listed in ASHRAE (1985).

\subsection{Solar energy modelling}

The useful solar energy collected is transferred to the hot liquid storage tank from which the generator of the absorption system is supplied with input thermal energy. Necessary equations for modelling solar energy are taken from Duffie and Beckman (1991).

$$
Q_{u}=A_{c} \eta_{c}
$$

Where $Q_{u}$ is the useful energy collected in system collectors, $A_{c}$ is the collector area, I is solar insolation and $\eta_{c}$ is the collector efficiency;

$$
\eta_{c}=F_{R}\left[(\tau \alpha)-U_{L} \frac{T_{i n}-T_{o}}{I}\right]
$$

In this equation, $\mathrm{F}_{\mathrm{R}}$ is the collector heat removal factor, $(\tau \alpha)$ is the transmittance-absorptance product, $\mathrm{U}_{\mathrm{L}}$ is overall heat transfer coefficient, $\mathrm{T}_{\text {in }}$ is the collector inlet temperature and $T_{\mathrm{o}}$ is the environment temperature. Perfect mixing within the tank is assumed. If the rate of heat addition and removal for a reasonable period of time $\Delta t$ are assumed to be constant, equations can be written for each time interval:

$$
T_{s}^{\text {new }}=T_{s}+\frac{\Delta t}{m_{s} C_{v w}}\left[Q_{u}-Q_{L}-Q_{s}\right]
$$
where $Q_{s}=(U A)_{s}\left(T_{s}-T_{o}\right), Q_{\mathrm{L}}$ is the extracted energy from the storage tank, $T_{s}$ is the main storage temperature for the period and $\mathrm{m}_{\mathrm{s}}$ is the storage tank mass. $(\mathrm{UA})_{\mathrm{s}}$ is taken as $11.1 \mathrm{~W} / \mathrm{K}$ as suggested by Duffie and Beckman (1991). In spite of the fact that (UA)s depends on the surface area of the storage tank, the average value of both $(\mathrm{UA})_{s}$ and the surface area of the storage tank are assumed on the basis of the fact that the surface area of the storage tank shows little change for selecting storage tank mass. Here, the heat transfer coefficient is assumed to be 0.72 $\mathrm{W} / \mathrm{m}^{2} \mathrm{~K}$.

An auxiliary heater at the exit of the storage tank boosts the temperature of the hot water from the storage tank temperature to the allowable reference temperature when the storage tank temperature drops below the allowable reference temperature. The auxiliary heater capacity is calculated as follows:

$$
\mathrm{Q}_{\mathrm{aux}}=\mathrm{mC}_{\mathrm{pw}}\left(\mathrm{T}_{\text {ref }}-\mathrm{Ts}\right)
$$


Where $\mathrm{m}$ is the mass flow rate used by the generator and $\mathrm{T}_{\text {ref }}$ is the minimum allowable hot water inlet temperature required for the generator to boil off the refrigerant from the refrigerant-absorbent solution.

The fraction of the total load met by non-purchased energy FNP is calculated as:

$$
\mathrm{FNP}=1-\mathrm{Q}_{\text {aux }} / \mathrm{Q}_{\text {load }}
$$

where $Q_{\text {load }}$ is exactly the same as $Q_{\text {gen }}$ which is the generator load.

\section{Input data required}

The inputs data required for simulating the system consists of the following: system nominal capacity, generator temperature range, condenser temperature range, evaporator temperature range, absorber temperature, ambient temperature range, generator and condenser pressure, evaporator and absorber pressure, mass flow rate from generator to condenser, mass flow rate from absorber to generator, mass flow rate from generator to absorber. The system has been designed for $10.5 \mathrm{~kW}$ constant cooling load. The outputs include the surface area of the system components, coefficient of performance (COP) and the fraction of the total met by non-purchased energy (FNP).

\section{Results and discussion \\ 3.1 Validation}

The computer program developed has been validated by comparing some of its results (FNP) with the similar study by Ileri (1995). It can be seen from Table 2 that, as compared with Ileri's 1995 study, the results of present study for reference temperature effects show the same general behaviour. Similarly, Ileri's study shows that a $353 \mathrm{~K}$ reference temperature is the best solution.

Table 2: Comparison of FNP for different reference temperature of the present study with those of Ileri's 1995 for the month of August

\begin{tabular}{ccc}
\hline$T_{\text {ref }}(K)$ & Present study FNP (\%) & Ileri FNP (\%) \\
\hline 353 & 100 & 94 \\
\hline 358 & 89 & - \\
\hline 363 & 69 & 58 \\
\hline 368 & - & 56 \\
\hline
\end{tabular}

Clearly, it can be said that there is a good agreement between the two studies.

\subsection{Simulation results}

Simulation results are discussed in this section for the performance of a $10.5 \mathrm{KW}$ solar driven lithium bromide absorption cooling system. Figure 2 depicts the effect of the hot water inlet temperatures $\mathrm{T}_{\mathrm{s}}$ on the system COP and flow ratio FR. It can be seen that an increase in this temperature resulted in the decreases of FR. This is due to increases in the mass fraction of concentration solution $\left(\mathrm{X}_{\mathrm{G}}\right)$. While with an increase in this temperature, COP increases.

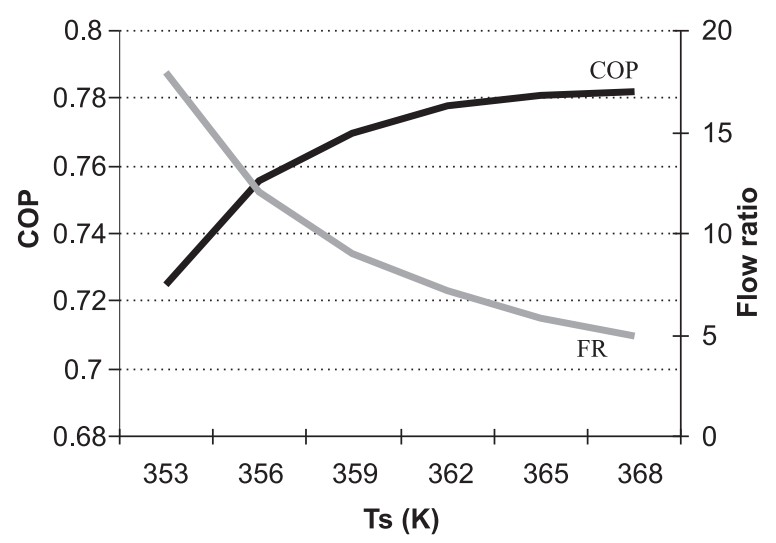

Figure 2: The effect of the hot water inlet temperatures on the system COP and FR $\left(T_{e}=280 \mathrm{~K}, Q_{L}=10.5 \mathrm{KW}, \mathrm{T}_{\mathrm{c}}=306 \mathrm{~K}\right)$

Figure 3 depicts the effect of the hot water inlet temperature on the surface area of the system components. It can be seen that increase in this temperature results in the decrease of the absorber and solution heat exchanger surface area. As flow ratio decreases, the thermal energy extracted from the absorber also decreases and hence the temperature of the absorber increases, which further resulted in the increase of logarithmic mean temperature difference $\left(\Delta \mathrm{T}_{\mathrm{m}}\right)$ in the absorber and solution heat exchanger. By decreasing the heat capacity and increasing $\Delta \mathrm{T}_{\mathrm{m}}$, heat transfer surface area normally decreases in these components.

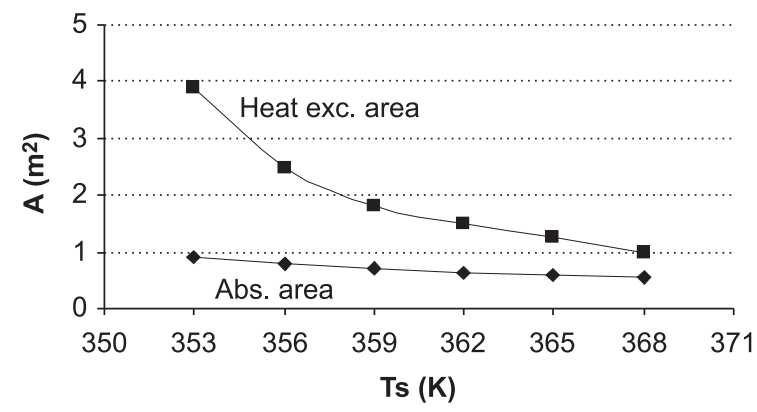

Figure 3: The effect of the hot water inlet temperatures on the surface area of the system components

$(\mathrm{Te}=280 \mathrm{~K}, \mathrm{QL}=10.5 \mathrm{KW}, \mathrm{Tcool}$, in $=291 \mathrm{~K})$

Figure 4 depicts the effect of the reference temperatures on FNP. The investigation is carried out between 353 and $368 \mathrm{~K}$ because the increment in 
the system COP slows down considerably after a certain temperature. Furthermore, boiling occurs above $368 \mathrm{~K}$ and this is not desirable. To investigate the effect of storage tank reference temperature on the FNP, three reference temperatures of the storage tank, 353, 358 and $363 \mathrm{~K}$ were taken into consideration. It can be seen from Figure 4 that the $353 \mathrm{~K}$ reference temperature seems to be the best. It gives better results than that of the higher reference temperatures. In this study, a reference temperature below $353 \mathrm{~K}$ is not investigated, because it could cause a decrease in the system COP. However, below the $353 \mathrm{~K}$ reference temperature, insufficient refrigerant vapour is driven from the liquid solution.

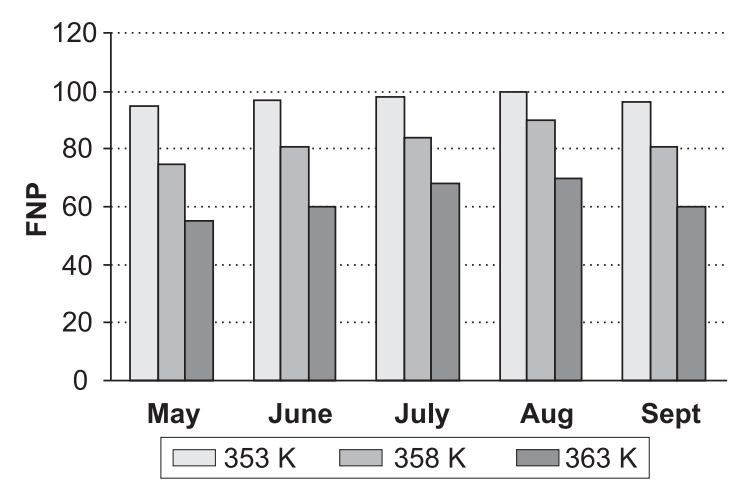

Figure 4: The effect of the reference temperatures on FNP

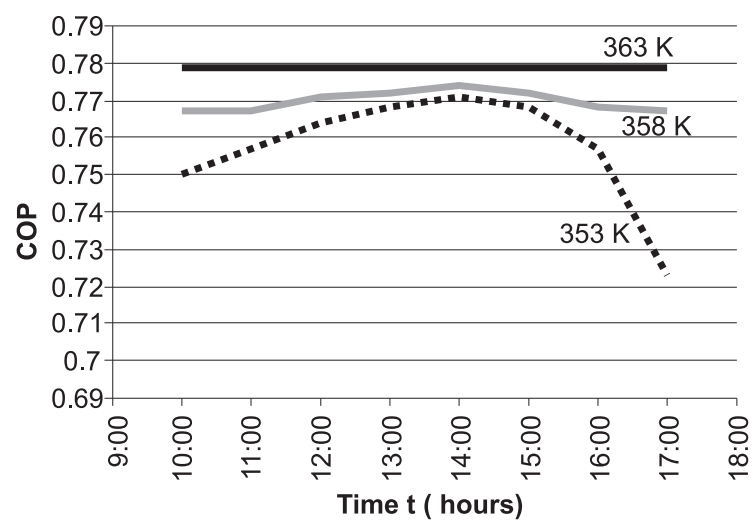

Figure 5: The effect of the reference temperatures on the system COP for a day in May

Figure 5 depicts the effect of the reference temperatures on the system COP for a day in May. As shown, unlike the effects caused by reference temperature on FNP, increasing the reference temperatures boosts the system COP. Also, COP remains unchanged at this high reference temperature of $363 \mathrm{~K}$.

\section{Conclusion}

From the above study the following results can be drawn.
1. The hot water inlet temperature is found to affect the surface area of some of the system components. Increasing this temperature decreases the absorber and solution heat exchanger surface area, while the dimensions of the other components remain unchanged.

2. Although high reference temperature increases the system COP and decreases the surface area of system components, lower reference temperature gives better results for FNP than high reference temperatures do. For this study, a $353 \mathrm{~K}$ reference temperature is the best choice.

\section{References}

Ameel T. A., Gee K. G. and Wood B. D., Performance predictions of alternative, low cost absorbents for open cycle absorption solar cooling, Solar Energy, 1995, 54(2), 65-73.

ASHRAE Handbook of Fundamentals, ASHRAE, Atlanta, 1985.

Duffie J.A. and Beckman W.A., Solar Engineering of Thermal Processes, Wiley, New York, 1991.

Haim I., Grossman G. and Shavit A., Simulation and analysis of open cycle absorption systems for solar cooling, Solar Energy, 1992, 49(6), 515-534.

Hammad M. A. and Audi M. S, Performance of a solar $\mathrm{LiBr}$-water absorption refrigeration system, Renew. Energy, 1992, 2(3), 275-282.

Hawlader M. N. A., Noval K. S. and Wood B. D., Unglazed collector/regenerator performance for a solar assisted open cycle absorption cooling system, Solar Energy, 1993, 50(1), 59-73.

Ileri A., Yearly simulation of a solar-aided R22-Degdme absorption heat pump system, Solar Energy, 1995, 55(4), 255-65.

Stoeker W. F. and Jones J. W., Refrigeration and Air Conditioning, International Edition. McGraw Hill, Singapore, 1982.

Wilbur P. J. and Mitchell C. E., Solar absorption air-conditioning alternatives, Solar Energy, 1975, 17, 193199.

Received 20 July 2005; revised 15 October 2005 